\title{
Effect of Salt Surfactant Interaction on Crystal Growth Observed Using Surface Enhanced Elipsometric Contrast (SEEC) Imaging
}

\author{
Rajesh Saini $^{1}$, Mohammad Haque ${ }^{2}$ and Ayrat Gizzatov ${ }^{1}$ \\ ${ }^{1}$ Aramco Americas, Houston, Texas, United States, ${ }^{2}$ Aramco Americas, Katy, Texas, United States
}

The effect of salt surfactant interaction on crystal growth of salt after evaporation of solution was studied by Surface Enhanced Elipsometric Contrast (SEEC) imaging technique. The crystallization behavior of salt can be greatly influenced by the surfactant type and can have major implications in food, paper, oil and gas industry. For instance, in oil and gas industry crystallization of salt in porous formation can plug the permeability of formation thus impeding hydrocarbon production. In this paper two distinct crystallization behavior of high salinity brine solution after evaporation were observed in presence of petroleum sulfonate mixed with anionic (sodium C14-16 Olefin Sulfonate) and a zwitterionic (cocamidopropyl hydroxysultaine) co-surfactant.

The crystal structures formed on the substrate is in the order of 10's of nanometers which the SEEC technique stands equivalents to $\mathrm{Z}$-axis resolution of atomic force microscopy (AFM). SEEC, a noninvasive (non-contact, atmospheric) technique, uses an antireflection-coated substrate which enhances the imaging contrast for the crystal thin film by 10 to 100 folds due to the reduction of the background signal. It was observed by SEEC that petroleum sulfonate in combination with anionic surfactant prevented the crystal formation and nucleation rate resulting in localized and spatially isolated circular shaped crystal growth as in Fig. 1. It also proves that the combination of these surfactant is stable at high salt concentration presumably due to passivation of nucleation sites. Whereas when petroleum sulfonate is mixed with zwitterionic surfactant in high salt conditions it resulted in rapid and branched shaped crystal growth with larger domains as in Fig. 2. Within the domain, a loosely packed (not fully grown crystal) and densely packed crystal regions were observed. This is because of the instability of the surfactant as well as formation of worm like micelles by zwitterionic co-surfactant that aided in the crystal growth. Fig. 3 shows the topographic measurements of the branched crystals formed in Fig. 2.

Experimental: Two surfactant blends were prepared by mixing petroleum sulfonate and co-surfactant in high-salinity brine. First blend was prepared by mixing $1 \mathrm{~mL}$ of $5 \mathrm{wt} \%$ of petroleum sulfonate (EOR 2095 from Chemtura, Inc.) in deionized (DI) water and $1.3 \mathrm{~mL}$ of 4 wt.\% of sodium C14-16 Olefin Sulfonate co-surfactant (WitconateTM AOS from AkzoNobel) in DI water. The second blend was formed by mixing $1 \mathrm{~mL}$ of $5 \mathrm{wt} . \%$ of petroleum sulfonate in deionized (DI) water and $1.3 \mathrm{~mL}$ of $4 \mathrm{wt} . \%$ of cocamidopropyl hydroxysultaine co-surfactant (Petrostep SB from Stepan Company) in DI water. These surfactant blends were mixed with $18 \mathrm{~mL}$ of synthetic high-salinity brine $(60,000 \mathrm{ppm}$ TDS including chlorides of sodium, calcium, and magnesium and sulfate of sodium) and solution evaporated on an especial substrate for crystallization to happen. The formed crystals were investigated by SEEC.

Acknowledgement: The authors would like to acknowledge Nanolane Inc. of Le Mans, France for their support in SEEC imaging. 

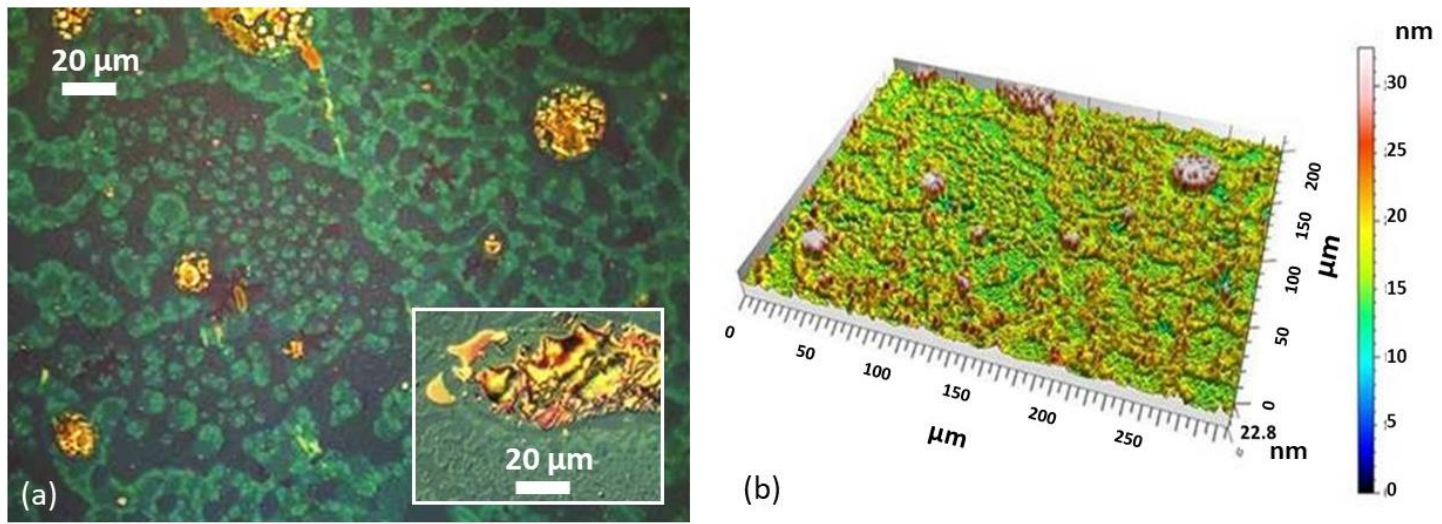

Classification: General Use

Figure 1. Salt crystallization after interactions of high salinity brine and blend of petroleum sulfonate and anionic (sodium C14-16 Olefin Sulfonate) (a) SEEC image, (b) 3D SEEC colorimetric image.
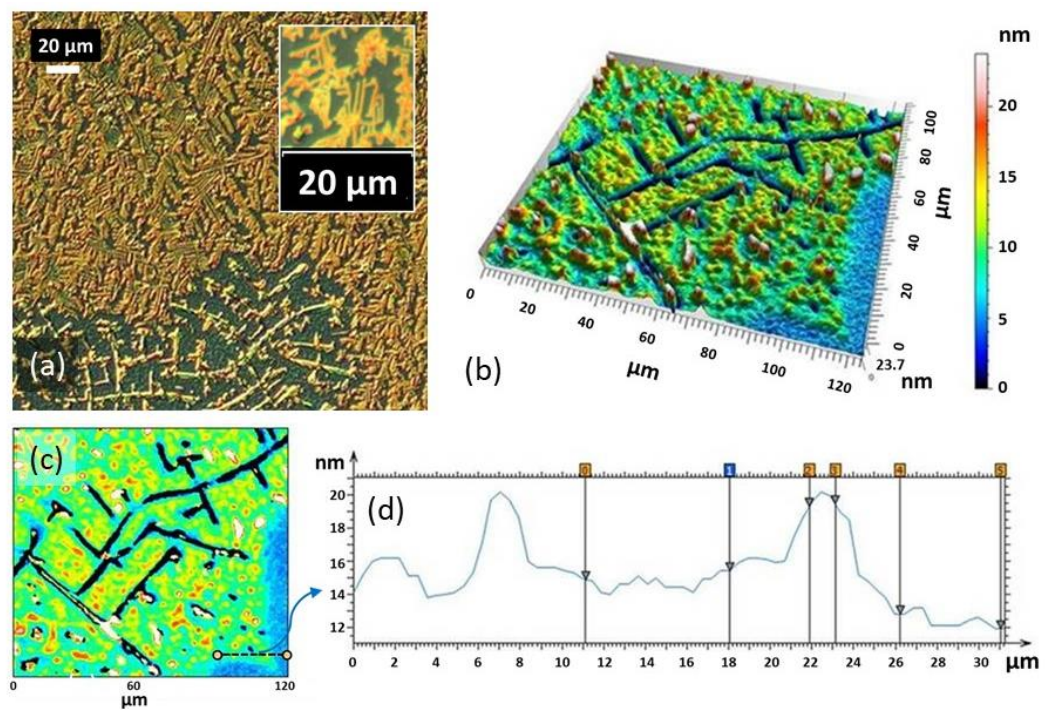

Classification: General Use

Figure 2. Salt crystallization after interactions of high salinity brine and blend of petroleum sulfonate and zwitterionic (cocamidopropyl hydroxysultaine) (a) SEEC image, (b) 3D SEEC colorimetric image, (c,d) topographic measurement of post-evaporated crystallized salt.

\section{References}

[1] Qazi et al., Langmuir, 33, 4260-4268, 2017.

[2] Montgomery et al., Nanotechnology, Science and Applications. 8, 31-44, 2015.

[3] Muckenhirn et al, Proc. of SPIE. Vol 9778, 97780R1. 2016.

[4] Ausserré et al., Optics Express. Vol. 15, No. 13. 8329-8339. 2007. 